\title{
Emergency procedural sedation in children
}

\author{
Maxim Ben-Yakov MDCM, Maala Bhatt MD MSc
}

Cite as: CMAJ 2020 October 5;192:E1162. doi: 10.1503/cmaj.200332

CMAJ Podcasts: author interview at www.cmaj.ca/lookup/doi/10.1503/cmaj.200332/tab-related-content

\section{1}

\section{Emergency procedural sedation is safe}

About $1 \%$ of children who visit an emergency department receive procedural sedation for painful procedures, including laceration repair, abscess incision and drainage, and orthopedic reductions. ${ }^{1}$ Sedation in healthy children is associated with a $1 \%$ frequency of serious adverse events, including apnea, hypotension and bradycardia., ${ }^{1,2}$

\section{Consider sedation with a single agent, such as ketamine, over drug combinations}

In a prospective cohort of 6295 children, procedural sedations using ketamine alone were associated with fewer adverse events and required less positive pressure ventilation than any other drug combination, which resulted in more completed procedures without unplanned hospital admissions. ${ }^{1}$ Laryngospasm occurred in $0.1 \%-0.3 \%$ of sedations. ${ }^{1,2}$ The only absolute contraindications to ketamine use are age younger than 3 months and a known or suspected psychotic disorder. ${ }^{3}$

\section{3}

\section{Premedication with ondansetron reduces postsedation nausea and vomiting}

Postsedation vomiting occurs in 5\% of children, and those who are older than 4 years old who are sedated using ketamine are at greatest risk. ${ }^{1,2}$ One randomized controlled trial showed that a single dose of ondansetron reduced vomiting in children who had been given ketamine in the emergency department and after discharge from $18.9 \%$ to $7.8 \%$ (number needed to treat $=9) .{ }^{4}$ Ondansetron is typically administered as a single dose 15-30 minutes before sedation by oral disintegrating tablet.

\section{4}

Premedication with opioids is associated with an increased risk of adverse outcomes

When opioids are administered in close proximity to sedation ( $\leq 30 \mathrm{~min}$ ), the risk of oxygen desaturation and vomiting in children increases (odds ratio 1.9 and 1.4 , respectively) compared with those receiving an opioid 3 hours before sedation. ${ }^{1,2}$ Recognizing the synergistic effect of opioids and sedatives should alert clinicians to the importance of the premedication agent and sedation timing.

Fasting status is not an independent predictor for aspiration Fasting guidelines are commonly not adhered to in the emergency department; however, we are unaware of a reported aspiration event associated with parenteral sedation in a child. In a prospective cohort study, half of the children did not adhere to fasting guidelines, and no association between fasting duration and adverse events was found. ${ }^{5}$

\section{References}

1. Bhatt M, Johnson DW, Chan J, et al. Risk factors for adverse events in emergency department procedural sedation for children. JAMA Pediatr 2017;171:957-64.

2. Bellolio MF, Puls HA, Anderson JL, et al. Incidence of adverse events in paediatric procedural sedation in the emergency department: a systematic review and meta-analysis. BMJ Open 2016;6:e011384.

3. Green SM, Leroy PL, Roback MG, et al. An international multidisciplinary consensus statement on fasting before procedural sedation in adults and children. Anaesthesia 2020;75:374-85.

4. Langston WT, Wathen JE, Roback MG, et al. Effect of ondansetron on the incidence of vomiting associated with ketamine sedation in children: a double-blind, randomized, placebo-controlled trial. Ann Emerg Med 2008;52:30-4.

5. Bhatt M, Johnson DW, Taljaard M, et al. Association of preprocedural fasting with outcomes of emergency department sedation in children. JAMA Pediatr 2018;172:678-85.

\section{Competing interests: None declared.}

This article has been peer reviewed.

Affiliations: Division of Emergency Medicine (BenYakov), Hospital for Sick Children, University of Toronto, Toronto, Ont.; Division of Emergency Medicine (Bhatt), Children's Hospital of Eastern Ontario, University of Ottawa, Ottawa, Ont.

Correspondence to: Maxim Ben-Yakov, maxim. benyakov@utoronto.ca

CMAJ invites submissions to "Five things to know about ..." Submit manuscripts online at http://mc. manuscriptcentral.com/cmaj 